\title{
Postpartum Depression Prevalence in a Tertiary Care Hospital in Mumbai, Maharashtra, India
}

\author{
Deepali P Kale ${ }^{1}$, Zenab Y Tambawala², Namrata M Rajput ${ }^{3}$
}

\begin{abstract}
Aim: To assess the prevalence and risk factors associated with postpartum depression in India.

Material and methods: Screening for postpartum depression was done with questionnaires distributed to our postdelivery women after informed consent. We used a 10-point questionnaire called "Edinburgh Postpartum Depression Scale" (EPDS), as it was easy to use and validate. We analyzed the data to identify risk factors and find the prevalence of postpartum depression in our patients over a 6-month period in a tertiary care hospital in central Mumbai which caters to low- and mid-income groups of patients.

Results: We found the prevalence of postdelivery depression identified by EPDS questionnaires at day 3 and day 14 of delivery to be $4 \%$.

Conclusion: This shows the necessity to address mental health problems in our postpartum women. If 1 in 25 women has serious mental health issues postdelivery, it can affect the immediate postpartum recovery of mother and also have significant negative impact on maternal and fetal bonding.

Clinical significance: The postpartum period which is immediately after delivery to 42 days later is an important and critical period for all mothers with physical, emotional, and psychological ramifications. Maternal mental health is an oft neglected area, and we need to provide more support after identification of such women.

Keywords: Cesarean delivery, Mental health, Postpartum depression.

Journal of South Asian Federation of Obstetrics and Gynaecology (2019): 10.5005/jp-journals-10006-1696
\end{abstract}

\section{INTRODUCTION}

The postpartum period which is immediately after delivery to 42 days later is an important and critical period for all mothers with physical, emotional, and psychological modifications. The exhaustion of labor and delivery, excitement of bringing forth a new life, and its demands have an effect on the mental health of all mothers.

Postpartum psychiatric illness has a wide spectrum ranging from the most common postpartum blues which is a minor adjustment disorder and resolves soon in just a few weeks with lifestyle adjustments and family support. The postpartum psychosis has much less prevalence which globally ranges from 0.89 to 2.6 per 1,000 births. ${ }^{1}$ It is a serious disorder which starts within first 4 weeks postpartum and needs hospitalization.

The incidences of postpartum depression in various studies have been in the range of $10-15 \%$. The most recent incidence reported from India is $22 \%{ }^{2}$

Postpartum depression can remain undiagnosed and if left untreated can lead to serious sequelae affecting both the mother and the infant. Postpartum depression can manifest immediately after the birth of the child or can be sequential with antenatal depression and needs treatment. ${ }^{3}$

Screening for postpartum depression is usually done with a 10-point questionnaire called "Edinburgh Postpartum Depression Scale" (EPDS). ${ }^{4}$ It is easy to use and validate. We routinely offer this scale as screening to all patients under our care. We enrolled patients into our study to identify risk factors and find the prevalence of postpartum depression in our patients.

Risks associated with undiagnosed postpartum depression can ruin the maternal and infants quality of life, and subsequent child growth and development. However, there is paucity of data from
1,3Department of Obstetrics and Gynecology, Nowrosjee Wadia Maternity Hospital, Mumbai, Maharashtra, India

${ }^{2}$ Department of Obstetrics and Gynecology, Dubai Hospital, Dubai, United Arab Emirates

Corresponding Author: Deepali P Kale, Department of Obstetrics and Gynecology, Nowrosjee Wadia Maternity Hospital, Mumbai, Maharashtra, India, Phone: +919503614668, e-mail: deepalikale13@ gmail.com

How to cite this article: Kale DP, Tambawala ZY, Rajput NM. Postpartum Depression Prevalence in a Tertiary Care Hospital in Mumbai, Maharashtra, India. J South Asian Feder Obst Gynae 2019;11(4):239-242

Source of support: Nil

Conflict of interest: None

India. Identification and evaluation of risk factors will prevent the severity of illness (Table 1).

Postpartum depression can ruin mother-infant bonding and it also affects subsequent development in childhood and infancy. Postpartum depression can predispose the mother to serious sequelae like chronic or recurrent depression, which may affect the mother-infant relationship, and child growth and development. ${ }^{5-7}$

Postpartum depression can cause greater cognitive, behavioral, and interpersonal problems as well as higher risk of being underweight and stunted in the children as compared to the children of nondepressed mothers. ${ }^{4-6}$

The estimate of the prevalence of postpartum depression in Indian mothers was $22 \%$. The higher incidence being observed in the developing countries as compared to the developed countries.

Postpartum depression which is left untreated may have longterm adverse effects. ${ }^{6}$ 
Table 1: Edinburgh Postpartum Depression Scale score on day 3 and day 14 and the demographic variables

\begin{tabular}{lll}
\hline & EPDS $^{*}<13$ & EPDS $>13$ \\
\cline { 2 - 3 } Day & $\begin{array}{l}\text { Postpartum depression not } \\
\text { present }\end{array}$ & $\begin{array}{l}\text { Postpartum depression } \\
\text { present }\end{array}$ \\
\hline Day 3 & 117 & 6 \\
Day 14 & 120 & 3 \\
\hline
\end{tabular}

\begin{tabular}{llll}
$\begin{array}{l}\text { Demographic } \\
\text { variables }\end{array}$ & EPDS $<13$ & EPDS $>13$ & p value \\
\hline $\begin{array}{l}\text { Age, mean }( \pm S D) \\
\text { years }\end{array}$ & $28.23( \pm 5.01)$ & $26.34( \pm 3.56)$ & 0.098 \\
$\begin{array}{l}\text { Education, mean } \\
( \pm S D) \text { years }\end{array}$ & $10.786( \pm 4.65)$ & $14.16( \pm 1.86)$ & 0.001 \\
$\begin{array}{l}\text { Income, mean }( \pm S D) \\
\text { Rs/month }\end{array}$ & $1,32,869( \pm 16426)$ & $20,000( \pm 16587)$ & 0.03 \\
$\begin{array}{l}\text { Family support } \\
\quad \text { Good }\end{array}$ & 117 & & \\
$\quad$ Not good & 0 & 2 & $0.02^{* *}$ \\
\hline
\end{tabular}

*EPDS, Edinburgh Postpartum Depression Scale

**Fisher's exact test

Though there is a steady decline observed in the maternal mortality rates in India, the focus of care should now also include reducing the comorbid conditions like postpartum depression.,

Recently, there has been an increase in the number studies addressing the issues of postpartum mental health in India but there is a lack of robust systematic evidence that looks not only at the overall burden of postpartum depression but also its associated risk factors.

The sociodemographic as well as clinical risk factors need to be identified in order to diagnose earlier in the postpartum period and treat the postpartum depression in an effective manner. There is a need for early screening of postpartum depression postdelivery. ${ }^{10}$

The simple and effective screening tools like EPDS have demonstrated high sensitivity and specificity for the diagnosis of postpartum depression. The English version documented an optimal threshold for screening postnatal depression with a score of more than 13 out of 30 which had a sensitivity of $86 \%$ and a specificity of $78 \%{ }^{4}$

\section{Materials and Methods}

We conducted a prospective observational study from 1st July 2016 to 31st December 2016. We screened postpartum patients on day 3 and day 14 by using a validated questionnaire-EPDS. ${ }^{4}$ Patients who scored more than 13 were managed in combined team with psychiatry for depression.

This is a study done at Nowrosjee Wadia Maternity Hospital, Mumbai, from 1st July 2016 to 31st December 2016. We are affiliated to KEM hospital where we referred the patients who have been screened for probable postpartum depression for psychiatric evaluation. Total 123 participants were enrolled in our study. We were able to screen all these participants for postpartum depression (Table 2).

Informed consent of all the participants was taken to view the case papers and the history sheet of the patient as part of the study and also patients were explained the details of importance of emotional well-being.

The primary objectives of the study were to identify proportion of patients at risk for early postpartum depression and the risk
Table 2: Clinical variables and postpartum depression

\begin{tabular}{lcll}
\hline & EPDS $<13$ & EPDS $>13$ & p value \\
\hline High-risk factor in current pregnancy & & \\
Present & 5 & 4 & 0.03 \\
Absent & 112 & 2 & \\
Total & 117 & 6 & \\
Intranatal history & & & 0.04 \\
Eventful (7) & 5 & 2 & \\
Uneventful (116) & 112 & 4 & \\
Total (123) & 117 & 6 & 0.01 \\
Personal experience of labor & & \\
Good & 102 & 2 & \\
Fair & 15 & 4 & \\
Total & 117 & 6 & \\
\hline
\end{tabular}

factors for early onset postpartum depression in women delivered at a tertiary care hospital in the city of Mumbai. The other objectives were to study and monitor affected patients and the treatment given to them.

The inclusion criteria were all deliveries after 24 weeks of gestation irrespective of the mode and outcome. We excluded all pregnancies less than 24 weeks and where patient was not willing to complete the questionnaire after informed consent.

We had 123 participants in our study. The screening tool, i.e., EPDS (attached at the end of article) is 10 questionnaire with points up to 30 . It is a screening test to identify women at risk of mental disorders who need to be evaluated and followed up. It is a well-established, easy to use, and validated scale used globally. Cox and Holden suggested a cutoff score of 13 or higher (sensitivity for identifying major depressive episode (MDE) $=86 \%$, specificity $=78 \%$, and positive predictive value $=73 \%)^{4}$ for postpartum depression screening in clinical settings.

On day 3, the women who had delivered at our hospital were given "language validated questionnaire" in our case, Marathi language so it would be easily understood by them and scoring was done. The validity, consistency, and reliability of EPDS* in Marathi language have been demonstrated in one study done in Wardha district, Maharashtra. ${ }^{11}$ Few of the patients were assessed with EPDS given in English after ensuring their comprehension of English.

Women who had scores more than 13 which suggested that they were 'at risk of probable depression' were managed in liaison with the psychiatrist.

Additionally, at the routine postnatal follow-up on day 14, a repeat questionnaire was offered to all participants and scoring was repeated. Participants whose score was more than 13 were managed accordingly.

After completion of interviews and the referrals for appropriate participants, the data were entered in the excel sheets and analyzed with IBM SPSS software (version 25.0). The demographic variables and the clinical variables were cross-tabulated with the EPDS score. The Chi-square test and Fisher Exact tests were used wherever appropriate and the $p$ value of $<0.05$ was considered as a test of significance. This study was approved by the Institutional Ethics committee of Nowrosjee Wadia Maternity Hospital, Mumbai.

\section{Results}

Total 123 patients were enrolled for our study and they were screened for the probability of postpartum depression. The 
Table 3: Other clinical variables

\begin{tabular}{llll}
\hline Variable & EPDS $<13$ & EPDS $>13$ & p value \\
\hline $\begin{array}{l}\text { Previous children's death } \\
\text { Positive }\end{array}$ & 6 & 0 & \\
$\begin{array}{l}\text { Bad obstetric history } \\
\quad \text { Present }\end{array}$ & 10 & 1 & \\
$\begin{array}{l}\text { Mode of delivery } \\
\quad \text { Normal vaginal }\end{array}$ & $64(55 \%)$ & $4(66 \%)$ & 0.56 \\
$\quad$ Instrumental vaginal & $2(0.017 \%)$ & $1(15.5 \%\}$ & \\
$\quad$ Cesarean delivery & $51(43.5 \%)$ & $1(15.5 \%)$ & \\
NICU stay of the baby & $0.21( \pm 0.411)$ & $0.16( \pm 0.4)$ & 0.1 \\
$\begin{array}{l}\text { Gender of the baby } \\
\quad \text { Male }\end{array}$ & 0.47 & 0.33 & 0.79 \\
$\quad$ Female & 0.53 & 0.66 & \\
Lactation status & & All & \\
$\quad$ Breastfeeding & 105 & None & \\
$\quad$ Formula feed & 12 &
\end{tabular}

demographic and clinical variables were plotted and crosstabulated with EPDS score (Table 3).

The mean age of study participants in our study was 28 years. Forty-two percentage of the patients were in age group of 26-30 years. Sixty-six percentage of participants were from middle socioeconomic class and 31\% were from low socioeconomic class. Sixty percentage of the participants were educated up to primary and secondary levels. Thirty-nine percentage were educated graduate and above. Only one participant was illiterate. A number of primipara and multipara in the study were 84 and 39 , respectively.

Out of the 123 participants, 6 participants scored EPDS $>13$ on day 3. The prevalence of Postpartum depression in our study was $4.8 \%$. These six participants were counseled and explained about the need for referral to psychiatrist at KEM Hospital. However, out of these, one patient refused to visit the psychiatrist as she thought it would stigmatized her being mentally compromised.

Diagnosis of postpartum depression was confirmed in all five patients who consulted and they were prescribed the medication Escitalopram and also advised meditation therapy. On postpartum day 14, again all 123 participants were screened with EPDS.

Amongst the participants screened on day 3 who had high probability of postpartum depression $(n=6), 3$ participants still scored high $>13$ on EPDS on day 14. For two participants, score was $<13$ EPDS and the one participant who refused to visit the psychiatrist also scored $<13$ EPDS. Amongst the 117 (EPDS $<13$ ), none of the participants turned positive (EPDS $>13$ ) at the 14th day.

Poor social and family support was observed in four of our patients who had high scores EPDS $>13$. The $p$ value for this variable was significant $(<0.05)$ which indicated that the good backup and support of the family was an important factor in the emotional well-being of the mothers. ${ }^{12}$

High-risk obstetrics factors emerging in the current pregnancy were noticed to be associated with high probability of postpartum depression. Amongst the six participants, four had the new high-risk factor in the current pregnancy like one had oligohydramnios; one had preeclampsia which was attributed to thrombophilia and she had sudden intrauterine fetal demise due to reversal of diastolic flow on color Doppler; one had antenatal exacerbation of third person hallucinations; and one had fetus diagnosed with congenital heart disease and she was beyond the limits of termination as she registered late after 20th week of pregnancy.
Table 4: Prevalence of postpartum depression in other studies

\begin{tabular}{|c|c|c|c|c|}
\hline Study, year & Location & $\begin{array}{l}\text { Sample } \\
\text { size }\end{array}$ & Scale used & Prevalence \% \\
\hline $\begin{array}{l}\text { Dubey et al., } \\
2012\end{array}$ & New Delhi & 506 & EPDS & 6 \\
\hline $\begin{array}{l}\text { Piacentini } \\
\text { et al., } 2009\end{array}$ & Bergamo & 595 & EPDS & 7.10 \\
\hline $\begin{array}{l}\text { Nakku et al., } \\
2006\end{array}$ & Uganda & 544 & SRQ-25, MINI & 6.10 \\
\hline $\begin{array}{l}\text { Agoub et al., } \\
2005\end{array}$ & Morocco & 144 & EPDS, MINI & $\begin{array}{l}6.9 \text { at } 6 \text { weeks, } \\
11.8 \text { at } 6 \text { months, } \\
5.6 \text { at } 9 \text { months }\end{array}$ \\
\hline
\end{tabular}

EPDS, Edinburgh Postpartum Depression Scale; MINI, Mini international neuropsychiatric interview

The intranatal history was found to have significant effect on the postpartum depression. Two patients out of the six who scored high on EPDS had significant history of labor. One had precipitate labor and another patient had induction of labor for intrauterine fetal demise. This variable also showed the $p$ value $<0.05$ which was significant.

Personal experience of labor was a variable which was interpreted and recorded in patients own term as there is no available scale or score for this.

Four patients amongst those with high probability for postpartum depression worded their experience of labor as not so good. They worded it as fearful, stressful, and they were anxious at the extremes as three had certain antenatal diagnosed factors like oligohydramnios, malformed fetus, and intrauterine fetal demise. One patient had precipitate labor and her worry was being a third gravida she wanted to have vaginal birth as there was no one to look after her other two children if she would land up undergoing cesarean section. The reasons were explored subsequently on discussion with them.

In our study, the previous bad obstetric history mode of delivery, neonatal intensive care unit (NICU) stay of the baby, gender of the baby, and lactation status of the mother were found to have insignificant association with postpartum depression (Table 4).

\section{Discussion}

Postpartum period is a critical period in women's life during which she undergoes wide range of emotional changes. Postpartum depression if left undiagnosed and untreated, can have serious consequences on mother and the infant. As shown by many studies, the mother-infant bonding as well as the infant development is ruined by the postpartum depression. ${ }^{5-7}$

This study is an attempt to look into the trends of risk factor which can have impact on the postpartum depression in an urban Indian population. The prevalence of postpartum depression in our study was $4.87 \%$.

The actual prevalence of postpartum depression in India is $22 \%$ according to the most recently reported evidence in Bulletin of WHO 2017.

The reason for lower prevalence of postpartum depression in our study is only speculative and can be addressed in further extended studies. The reason being the small sample size may be one of the major limitations of our study and is attributed to the reluctant attitude of the delivered women to participate in the study as this involved the reference and consultation with psychiatrist. This could be the reason many women did not take our advice to 
visit a psychiatrist is still considered as a stigma in Indian cultural background and many women did not wished for that.

The study has shown the factors like poor social or family support, eventful intranatal history, emergence of new highrisk factor in current pregnancy, and poor personal experience of labor by the patients have high probability of postpartum depression.

Age and socioeconomic status level of education did not show significant association with the postpartum depression in our study. Results from other studies may not be coherent with our study as these variables are dependent on the various demographical characteristics of the population under study and vary accordingly. ${ }^{13}$

Other studies done in other parts of India like New Delhi and Andhra Pradesh have shown significant association between these factors and the postpartum depression (Table 4). ${ }^{12,14}$

EPDS was used as effective and simple screening tool which is well-validated in terms of sensitivity $92 \%$ and specificity $96 \% .^{11}$ EPDS have been given to our study participants in English and Marathi. The validity of EPDS in Marathi language has been demonstrated in study done by Khare et al. ${ }^{11}$

Out of six participants who were screened positive for probable postpartum depression were referred to psychiatry department of KEM hospital. The one who refused to consult the psychiatrist had assured us that her family will take care of her and she was afraid of being stigmatized or being labeled as mentally compromised. The help-seeking behaviors for the problems like postpartum depression is not extensively studied, especially in India where the cultural norms and pressures still rule the behaviors of women. ${ }^{15}$

This study is a small step to identify the problem of postpartum depression which is much more prevalent and is still unspoken about.

The study highlights the trend in the risk factors like the developing a good social and family support may be helpful for the emotional well-being of mothers, also to provide comfort to mothers in the intranatal period and smoothening her personal experience of labor is the key element which needs to be further studied in details. It also highlights the importance of early screening for postpartum depression as three participants who had scored positive on day 14 were diagnosed by the psychiatrist with major depressive episode and were treated for the same.

The study also focus on the importance of having liaison with the psychiatry is essential to miss any underlying organic disorder in the women and to have proper and complete care.

It also brings out that the underlying stigma associated with mental health problems still exists in our society and it can hamper the help-seeking behavior of the women and their families.

The sample size was small and so the interpretation of the actual burden of the problem of postpartum depression needs to be studied further with larger sample size in the future.

\section{Conclusion}

Our study highlighted the risk factors for postpartum depression which can have impact on emotional well-being and subsequent quality of life of patients. The prevalence of early postpartum depression in our study is $4.8 \%$. Stigma of referral to psychiatrist can interfere with compliance of further treatment. Presence of psychiatrist in the hospital would be beneficial.

We have concurrence of our study results with other studies in factors like family support, new high-risk factor, eventful intranatal history, and personal experience of labor.
The study shows that using screening scales like EPDS should be feasible and should be the norm for all patients to provide care for the complete physical and mental well-being of mother and child.

\section{ACKNOWLedgments}

We would like to acknowledge Dr KR Damania, Unit Head, NW Maternity Hospital for his constant support and guidance, and all patients who participated in our study for their valuable time.

\section{References}

1. VanderKruik R, Barreix M, Chou D, et al. The global prevalence of postpartum psychosis: a systematic review. BMC Psychiatry. 2017;17(1):272. DOI: 10.1186/s12888-017-1427-7.

2. Upadhyay RP, Chowdhury R, Salehi A, et al. Postpartum depression in India: a systematic review and meta-analysis. Bull World Health Organ 2017;95(10):706-717C. DOI: 10.2471/BLT.17.192237.

3. Stewart $D E$, Robertson $E$, Dennis $C L$, et al. Postpartum depression: literature review of risk factors and interventions. Toronto: University Health Network Women's Health Program; 2003. Available from: http://www.who.int/mental_health/prevention/suicide/lit_review_ postpartum_depression.pdf.

4. Cox JL, Holden JM, Sagovsky R. Detection of postnatal depression: development of the 10-item Edinburgh Postnatal Depression Scale. Br J Psychiatry 1987;150(6):782-786. DOI: 10.1192/bjp.150.6.782.

5. Field T. Postpartum depression effects on early interactions, parenting, and safety practices: a review. Infant Behav Dev 2010;33(1):1-6. DOI: 10.1016/j.infbeh.2009.10.005.

6. Surkan PJ, Kennedy CE, Hurley KM, et al. Maternal depression and early childhood growth in developing countries: systematic review and meta-analysis. Bull World Health Organ 2011;89(8):608-615D. DOI: 10.2471/BLT.11.088187.

7. Sohr-Preston SL, Scaramella LV. Implications of timing of maternal depressive symptoms for early cognitive and language development Clin Child Fam Psychol Rev 2006;9(1):65-83. DOI: 10.1007/s10567-0060004-2.

8. Dwenda G. The effectiveness of various postpartum depression treatments and the impact of antidepressant drugs on nursing infants. J Am Board Fam Med 2003;16(5):372-382. DOI: 10.3122/ jabfm.16.5.372.

9. Trends in maternal mortality: 1990 to 2015: estimates by WHO, UNICEF, UNFPA, World Bank Group and the United Nations Population Division. Geneva: World Health Organization; 2015. Available from: http://apps.who.int/iris/bitstream/10665/194254/1/9789241565141_ eng.pdf?ua $=1$.

10. Kruthika K, Udayar SE, Mallapur MD. An epidemiological study of postnatal depression among women availing maternal health services in rural areas of Belagavi, Karnataka, India. Int J Community Med Public Health 2017;4(3):759-763. DOI: 10.18203/2394-6040. ijcmph20170754.

11. Khare M, Dhande N, Mudey A. Validity and reliability of Marathi version of Edinburgh Postnatal Depression Scale as a screening tool for post natal depression. Nat J Community Med 2017;8(3):116-121.

12. Nigam A, Prakash A, Maheshwari N. Postpartum depression in an Indian community: more prevalent less addressed issue. Int J Reprod Contracept Obstet Gynecol 2016;5(8):2691-2695. DOI: 10.18203/23201770.ijrcog20162648.

13. Di Florio A, Putnam K, Altemus $M$, et al. The impact of education, country, race and ethnicity on the self-report of postpartum depression using the Edinburgh Postnatal Depression Scale. Psychol Med 2017;47(5):787-799. DOI: 10.1017/S0033291716002087.

14. Lakshmi Bhuvana G, Sripada R, Devi Priya S, et al. Prevalence of Postpartum Depression at an Indian Tertiary Care Teaching Hospital. Int J Pharm Clin Res 2016;8(6):616-618.

15. Thorsteinsson EB, Loi NM, Farr K. Changes in stigma and helpseeking in relation to postpartum depression: non-clinical parenting intervention sample. PeerJ 2018;6:e5893. DOI: 10.7717/peerj.5893. 